\title{
Interfragmentary approach total hip replacement in unstable intertrochanteric femur fracture in elderly shows better clinical result compare to standard posterior approach
}

\begin{abstract}
Introduction: Hip fracture is the most common fracture in elderly patients, with the rate of morbidity increasing is the main issues. The clinical as well functional outcomes are influenced by many factors, which includes patient condition, type of fracture, and definite treatment weather replacement or fixation.

Patient and methodology: We carry out study in our center 54 patients presented to our center with unstable Intertrochanteric Femur Fracture with age more than 70 years old. Twenty Six of them (group 1) underwent standard posterior approach and 28 (group 2) underwent interfragmentary approach. Those patient with cognitive disorder and other neuromuscular disorder was excluded in this study. All of them was treated with Uncemented Total Hip Repalcement and Trochanteric Cable Plate with same type of implant.

Statistical analysis: Latest version of SPSS software package was used for the statistical analysis of data. Categorical measurements were given as numbers and percentage values, whereas continuous measurements were given as mean and SD values (median and minimum-maximum when necessary). Their mean age was 82 (70-90) years, 14 males and 40 females with BMI is 20.2 (19.8-22.1.).

Result: According to comparison of the groups, it was found that the rate of dislocation was statistically significantly higher in patient underwent posterolateral approach compare to interfragmentary approach. Trochanteric non union also is higher in group 1 compare to group 2 .

Conclusion: The option of Total Hip Repalcement with Trochanteric Grip Plate in elderly patient with osteoporotic bone through interfragmentary approach, give immediate stability and allow weight bearing and show good functional outcome with no complication at short term period.
\end{abstract}

Volume 13 Issue 6 - 202 I

Azhar M, Omer F Bilgen

Medicabil Hospital, Bursa, Turkey

Correspondence: Muhammad AzharAbdullah, Medicabil Hospital, Bursa, Turkey, Email ardstik82@yahoo.com

Received: December 04, 202I | Published: December 17, 2021

\section{Introduction}

Pertrochanteric and Transtrochanteric fractures in elderly patients one of factors which causes high morbidity and mortality. From previous reported studies ${ }^{1-3}$ shows $30 \%$ of mortality within 1 year from the injuries. Of all the hip fractures intertrochanteric fracture constitute $45 \% .^{1}$ If the patients receive early optimum treatment for the fractures may help them to return back to premorbid functional status.

Hip fracture can be classified into intra and extra capsular. Intra capsular fracture referring to head of femur as well neck of femur while extra capsular referring to basal neck, intertrochanteric an subtrochanteric fractures. Intertrochanteric can be further classified according to $\mathrm{AO}$ classification as $31 \mathrm{~A} 1,31 \mathrm{~A} 2$, and $31 \mathrm{~A} 3$ types according, ${ }^{3}$ where type $\mathrm{A} 2$ and $\mathrm{A} 3$ represented unstable fractures. Based on Evans- Jensen classification intertrochanteric fracture can be classified to type I, II, III, IV, and V where type IV, and V are considered as unstable. Surgical intervention for these fractures especially in elderly allow early rehabilitation and functional recovery which indirectlt reduce the rate of morbidity and mortality. ${ }^{5}$ In study done by Simunovic et al. found that surgical intervention which was done as early 72 hours from onset of injuries will reduce risk of death and post-surgery complication. ${ }^{6}$
In general all the stable hip fracture which is extracapsular gold standard treatment is ostaeosynthesis but in our population $33 \%$ is classify as unstable hip fractures. ${ }^{7}$ In elderly patient with osteoporotic bone internal fixation is highly associated with complication such implant cut out or non-union which end up for revision surgery. Post osteosynthesis patient need to undergo long phase of rehabilitation with long bed rest for bony union before full weight bearing. This will further increase the risk of developing deep vein thrombosis which might fatal if when to Pulmonary Embolism. ${ }^{8,9}$

From the review of previous study, Total Hip Replacement (THR) can be the option of treatment in elderly and osteoporotic patients which presented with unstable intertrochanteric fracture (Evans Type IV and V). The most common complication in elderly patient which underwent THR is dislocation. ${ }^{10}$ The rate of dislocation is around $1 \%$ to $22 \%$ from previous study ${ }^{11}$ and most of it is associated with type of surgical approach. This is because in elderly most of the soft tissue component for primary and secondary hip stability is lax. Further destruction of the soft tissue will lead to total weakness of the muscle and ligament serrounding the hip joint. It is reported that rate of dislocation is higher in standard posterolateral approach where the capsule and external rotators is been incised during surgery to perform THR. However the dislocation rate can be reduced if the posterior structure is been repair well and the soft tissue is not lax. ${ }^{12}$ 


\section{Patients and methods}

This retrospective comparative study from our center from year September 2017 until 2019. Fifty four unstable Intertrochanteric (Evan IV and V Classification) Femur fracture in elderly was operated between 2017 and 2019 at our hospital. Among these fractures, 26 Group $1(\mathrm{n}=26)$ of them under went classical Posterior Approach which was before Mei 2018 and 28 Group $2(n=28)$ patients underwent Interfragmentary Approach for THR with Trochanteric Cable Plate after June 2018. All surgeries were performed by single well experience surgeon. Among the patients included in the study, all
54 patients were implanted using Uncemented Total Hip Replacement with Trochanteric Cable Plate from same company as well the size of Femoral head size was same for all patients which was $36 \mathrm{~cm}$.

In groups 1 and 2 the mean age was $82.5 \pm 4.5$ (Grp 1) and 80.1. \pm 7.6 (Grp 2) years, respectively. Nineteenth patients $(73.1 \%)$ patients in Group 1 was female while 7 of them was male while in Group 2 twenty one $(75 \%)$ patients was female and 7 of them was male. In Table 1 it shows the demographic characteristics and morbidities of patients of all patients. This include body mass index (BMI), status according to American Society of Anesthesiologists (ASA) classification and gender, according to each group.

Table I Distribution of the demographic and clinical characteristics of the patients included in the study by groups and statistical analysis of the differences between the two groups

\begin{tabular}{llll}
\hline & $\begin{array}{l}\text { Posterolateral } \\
\text { (Group I) }\end{array}$ & Interfragmentary (Group2) & P value \\
\hline (n\%) 26 & $\mathbf{( n \% )} \mathbf{2 8}$ & \\
\hline $\begin{array}{l}\text { Gender } \\
\text { Female } \\
\text { Male }\end{array}$ & 19 & 21 & 0.543 \\
Age & 7 & 7 & 0.321 \\
BMI & 82.5 & 80.1 & 0.432 \\
ASA & 21.3 & 22.4 & 0.212 \\
I & & & \\
2 & $17(65)$ & $24(85)$ & 0.321 \\
3 & $6(23)$ & $3(10)$ & 0.765 \\
Prosthesis & $3(12)$ & I (5) & 0.543 \\
Femoral Head Size & Uncemented Total Hip & Uncemented Total Hip & \\
& Trochanteric Grip Plate with 4 cable wire & Trochanteric Grip Plate with 4 cable wire & 0.654 \\
\hline
\end{tabular}

All patients which participated in this study their record was reviewed. Surgical timing, early mortalities, amount of blood loss during surgery and the time from admission to surgery was recorded as well. Patient follow up records was reviewed in order to investigate and analyze the complications such as infection, mortality and dislocation between two groups for comparison Patient with poor cognitive and unable to obey command with neuromuscular disease such as Parkinson Disease, Alzheimer Disease was excluded.

\section{Surgical procedure}

\section{Standard posterior approach}

Under this technique patient In Group 1 was included, Patient was place in lateral position on surgical table the operating side facing surgeon. The skin incision is made at the posterior border of femur then through subcutenous then to tensor fascia lata. Bursae around the trochanteric will be removed, then glutes maximus muscle is split along its proximal fibers with finger dissection. Piriformis tendon is identified then the short rotators (Superior Gamelli, Internal Rotator, Inferior Gmelli) is identified before it is separated from the attachment at the trochanter then it is reflected posterior indirectly the sciatic will be protected. Then, the joint capsule is expose and capsulotomy was performed in T-shaped to approach fractured femoral head. For femur preparation, femur is internally rotated, uncemented femoral stem was placed. Trochanteric grip plate and cable was used to fix the fracture fragment at greater trochanteric region. Short rotators and capsule were sutured back to its original attachment.

\section{Interfragmentary approach}

Patients in Group 2 were also subjected to the same position and with same incision through skin, subcutenous and fascia. Then, femoral head was removed through the fracture side without disturbing the insertion part of the short rotators and capsule (Figures $1 \& 2$ ). The same method was used for femoral stem implantation and fixation of the trochanter fracture.

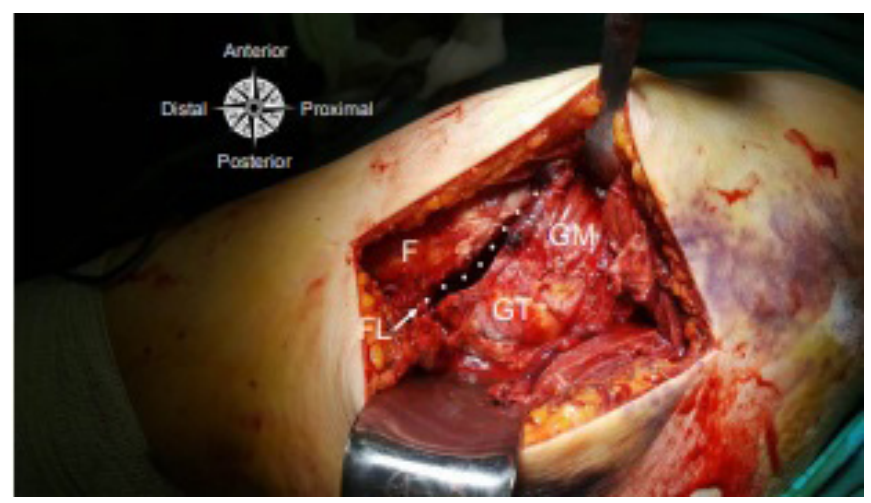

Figure I Interfragmentary approach surgical technique. Note: Accessing to the femoral head from the fracture line on the proximal femur indicated by dots.

F, femur; FL, fracture line; GM, gluteus medius; GT, greater trochanter. 


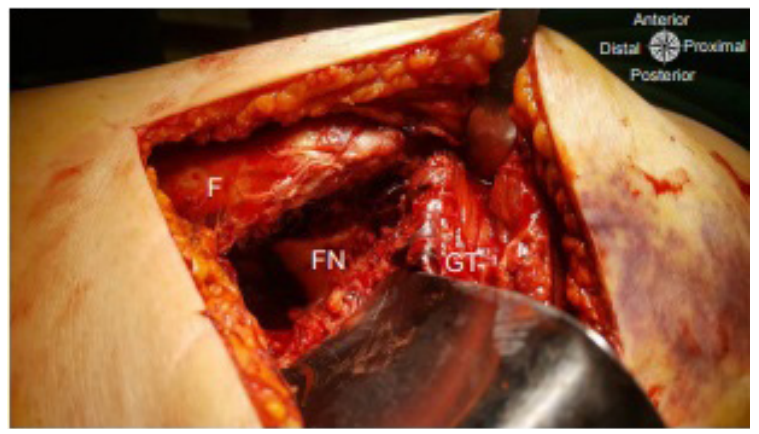

Figure 2 Interfragmentary approach surgical technique. Note: Discarding the proximal part after accessing through the fracture line and reaching the femoral neck.

F, femur; FN, femoral neck; GT, greater trochanter.

\section{Statistical analysis}

The SPSS software latest version was used for statistical analysis of the data. Continuous measurement were given as mean and SD values (median and minimum - maximum when necessary) and Categorical measurements were given percentage values and numbers. For comparing categorical variables Chi - Square test was used. Distributions were analysed on comparing continuous variables between the groups. Mann- Whitney U test was used for variables that did not have parametric distribution where as Student's t-test was used for variables that had a parametric distribution. The $p$ value $<0.05$ was accepted as Statistical significance for the al the tests.

\section{Results}

From the statistical analysis it was found that the rate of dislocation post THR was higher in Group 1 which was statistically significant compared to Group 2 (P 0.04). Table 2 show the comparison of all studied parameters. However in term of demographics and clinicals characteristics in both groups revealed there is no significant different.

It was found that trochanteric non-union was higher in group 1 which is direct posterior approach. The standard posterior surgical approach resulted in a statistically significant increase in the rate of dislocation $(p=0.04)$. In term of fixation method there was no significant difference was found. Independent risk factors that affect the formation of dislocation in a patient were identified. It was found that trochanteric non-union, and use of standard posterior surgical approach increased the risk of developing dislocation.

Table 2 Comparison of the two surgical techniques

\begin{tabular}{lllll}
\hline Parameter & $\begin{array}{l}\text { Standard Posterior } \\
\text { Approach(n=26) }\end{array}$ & $\begin{array}{l}\text { Interfragmentary } \\
\text { Approach } \\
\mathbf{( n = 2 8 )}\end{array}$ & $\begin{array}{l}\text { Total } \\
(\mathbf{n = 5 6 )}\end{array}$ & P-value \\
\hline $\begin{array}{l}\text { Surgical Duration, minutes } \\
\text { Dislocation (\%) }\end{array}$ & $72 \pm 10.4$ & $68 \pm 10.5$ & $70 \pm 10.9$ & 0.003 \\
$\begin{array}{l}\text { Yes } \\
\text { No }\end{array}$ & $3(13)$ & $0(0)$ & & \\
Deep Infection (\%) & $23(87)$ & $28(100)$ & $3(5.3)$ & 0.044 \\
Yes & $1(3.8)$ & & $51(91)$ & \\
No & $25(96.1)$ & $2(7.1)$ & $3(5.3)$ & 0.342 \\
Mortality in 3 months (\%) & & $26(92.9)$ & $51(94.7)$ & \\
Yes & $0(29.2)$ & & & \\
No & $26(70.8)$ & $0(20.3)$ & $0(24.1)$ & 0.543 \\
$\begin{array}{l}\text { Trochanteric Non Union (\%) } \\
\text { Yes }\end{array}$ & $7(26.9)$ & $28(79.7)$ & $56(75.9)$ & \\
No & $19(73.1)$ & $2(7)$ & $9(16.1)$ & 0.765 \\
& & $26(93)$ & $45(83.9)$ & \\
\hline
\end{tabular}

\section{Discussion}

From the study which we have done, it shows that, interfragmentary approach which could be done through the fracture at the trochanter without incision of short rotators and capsule to perform THR in elderly and osteoporotic bone in unstable Intertrochanteric Fracture Evans IV -V more effective in reducing the rate of dislocation which is an important problem that increase morbidity in Total Hip Arthroplasty in comparison to standard posterior approach. The statistical analysis concerning incidence of dislocation shows that the difference between the two groups was statistically significant $(p=0.04$ ).

Interfragmentary approach reduced the risk of dislocation and indirectly minimize the blood loss since the short rotators and capsule is not been incised. The surgery is performed at a distance from sciatic nerve which is at risk in the standard posterior approach. Concerning about non union, interfragmentary approach give better union rate regarding trochanteric fixation. Since the posterior vascular structures are preserved, indirectly the vascular support of the fracture fragment is not been compromised which ultimately provide a better union. By preserving the short rotators, It is also advantageous for patient undergo rehabilitation and muscle strength.

Some of previous studies revealed there is some other factors apart from surgical approach (gender, mental health status, fixation method, time of surgery, etc) that have an impact on the risk of dislocation following Total Hip replacement. ${ }^{15-23}$ The relationship between femoral head size, time to surgery from injuries, gender and fixation method were also analysed irrespective to surgical approach. In term of fixation method weather cemented or uncemented Total Hip Replacement there is no difference in term of dislocation rate. ${ }^{16-18}$ By using larger head of femur, the risk of dislocation is reduced since the ' jumping distance' increase. In our patient all of them were use same size of femoral head which where $36 \mathrm{~mm}$.

From our research there is no correlation between increased time of surgery and rate of dislocation $(p=0.320)$. Most of patient is been operated not more than 48 hours from the time of injuries. Two 
previous studied Madanat et al. ${ }^{20}$ and Salem et al. ${ }^{21}$ have shown that there was a direct correlation between time of admission to hospital until surgery and dislocation. However in their studies reported that exceeding 24 and 48 hours could increase the risk of dislocation.

Generally dislocation develops within first year post surgery as indicated in the literature. ${ }^{22}$ This study was retrospective design which one of the limitation and the mean follow up period investigating long term complication which was only 1 year period is also one of the weakness of this study. In future prospective randomized comparative studies comparing hip approaches for Total Hip replacement should be considered.

Previous studies were only concentrating on partial hip replacement and studies was carry out on the effect of surgical approach on the rate of dislocation following hemiarthroplasty. Our study was concentrating on Total Hip Arthroplasty in stead of hemiarthroplasty with cable trochanteric hook plate which provide immediate stability.

According to meta-analysis and registry data, it is show that the rate of dislocation is higher in the posterior approach as compared to the anterolateral approach. ${ }^{24,25}$ Charnley first describe Transtrochanteric approach in primary total hip arthroplasty, ${ }^{26}$ followed by Bombaci which described on Hemiarthropalsty for intertrochanteric fractures involving access through the trochanteric fracture line. However, there are no comparative and detailed studies concerning this approach. This study has shown that the rate of dislocation in interfragmentary approach performed from the fracture line was lower in comparison to the standard posterior approach.

\section{Conclusion}

The risk of dislocation post Total hip Replacement in elderly patients with unstable intertrochanteric fracture with osteoporotic bone can be reduced significantly by using Interfragmentary approach rather then standard posterior approach by preserving the anterior and posterior structures. For immediate stability and better union rate trochanteric grip can been use for the trochanteric fragments.

\section{Acknowledgments}

None.

\section{Conflicts of interest}

The authors declare no conflicts of interest.

\section{References}

1. Hassankhani EG, Omidi-Kashani F, Hajitaghi H, et al. How to treat the complex unstable intertrochanteric fractures in elderly patients? DHS or arthroplasty. Arch Bone Jt Surg. 2014;2(3):174-179.

2. Abrahamsen B, van Staa T, Ariely R, et al. Excess mortality following hip fracture: a systematic epidemiological review. Osteoporos Int. 2009;20(10):1633-1650.

3. Panula J, Pihlajamäki H, Mattila VM, et al. Mortality and cause of death in hip fracture patients aged 65 or older: a population-based study. BMC Musculoskelet Disord. 2011;12(1):105.

4. Evans EM. The treatment of trochanteric fractures of the femur. $J$ Bone Joint Surg Br. 1949;31B(2): 190-203.

5. E T. Hip fractures in the elderly: operative versus nonoperative management. Singapore Med J. 2016;57(4):178-181.

6. Simunovic N, Devereaux PJ, Sprague S, et al. Effect of early surgery after hip fracture on mortality and complications: systematic review and metaanalysis. CMAJ. 2010;182(15):1609-1616.
7. Grimsrud C, Monzon RJ, Richman J, et al. Cemented hip arthroplasty with a novel cerclage cable technique for unstable intertrochanteric hip fractures. J Arthroplasty. 2005;20(3):337-343.

8. Sheikh IS. Intertrochanteric femur fracture in elderly treated with bipolar vs DHS - a prospective study. Journal of Medical Thesis. 2014;2(2):4549.

9. Rae PJ, Hodgkinson JP, Meadows TH, et al. Treatment of displaced subcapital fractures with the Charnley-Hastings hemiarthroplasty. $J$ Bone Joint Surg Br. 1989;71(3):478-482.

10. Petersen MB, Jørgensen HL, Hansen K, et al. Factors affecting postoperative mortality of patients with displaced femoral neck fracture. Injury. 2006;37(8):705-711.

11. Bhandari M, Devereaux PJ, Swiontkowski MF, et al. Internal fixation compared with arthroplasty for displaced fractures of the femoral neck. A meta-analysis. J Bone Joint Surg Am. 2003;85(9):1673-1681.

12. Ko CK, Law SW, Chiu KH. Enhanced soft tissue repair using locking loop stitch after posterior approach for hip hemiarthroplasty. $J$ Arthroplasty. 2001;16(2):207-211.

13. Bombaci H. Transtrochanteric approach in intertrochanteric femur fractures. J Trauma. 2008;65(5):1171-1173.

14. Jones $\mathrm{C}$, Briffa N, Jacob J, et al. The dislocated hip hemiarthroplasty: current concepts of etiological factors and management. Open Orthop J. 2017;11:1200-1212.

15. Langslet E, Frihagen F, Opland V, et al. Cemented versus uncemented hemiarthroplasty for displaced femoral neck fractures: 5-year followup of a randomized trial. Clin Orthop Relat Res. 2014;472(4):1291-1299.

16. Deangelis JP, Ademi A, Staff I, et al. Cemented versus uncemented hemiarthroplasty for displaced femoral neck fractures: a prospective randomized trial with early follow-up. J Orthop Trauma. 2012;26(3):135140.

17. Figved W, Opland V, Frihagen F, et al. Cemented versus uncemented hemiarthroplasty for displaced femoral neck fractures. Clin Orthop Relat Res. 2009;467(9):2426-2435.

18. Howie DW, Holubowycz OT, Middleton R. Large Articulation Study Group. Large femoral heads decrease the incidence of dislocation after total hip arthroplasty: a randomized controlled trial. J Bone Joint Surg Am. 2012;94(12):1095-1102.

19. Madanat R, Mäkinen TJ, Ovaska MT, et al. Dislocation of hip hemiarthroplasty following posterolateral surgical approach: a nested case-control study. Int Orthop. 2012;36(5):935-940.

20. Salem KMI, Shannak OA, Scammell BE, et al. Predictors and outcomes of treatment in hip hemiarthroplasty dislocation. Ann R Coll Surg Engl. 2014;96(6):446-451.

21. Abram SG, Murray JB. Outcomes of 807 Thompson hip hemiarthroplasty procedures and the effect of surgical approach on dislocation rates. Injury. 2015;46(6):1013-1017.

22. Ninh CC, Sethi A, Hatahet M, et al. Hip dislocation after modular unipolar hemiarthroplasty. J Arthroplasty. 2009;24(5):768-774.

23. Varley J, Parker MJ. Stability of hip hemiarthroplasties. Int Orthop. 2004;28(5):274-277.

24. Rogmark C, Fenstad AM, Leonardsson O, et al. Posterior approach and uncemented stems increases the risk of reoperation after hemiarthroplasties in elderly hip fracture patients. Acta Orthop. 2014;85(1):18-25.

25. Charnley J. Low Friction Arthroplasty of the Hip. Theory and Practice. Berlin, Heidelberg, New York: Springer; 1979.

26. Patil A. Role of cemented bipolar hemiarthroplasty for comminuted inter-trochanteric femur fracture in elderly osteoporotic patients through a modified transtrochanteric approach - "SION Hospital Modification". IOSR-JDMS. 2013;9(4):40-47. 
27. Pradeep C, Anuj A, Abhishek G. Treatment of comminuted unstable intertrochanteric fracture in elderly patients with cemented bipolar prosthesis Indian J Orthop Surg. 2015;1(4):255-260.

28. Simmermacher RK, Ljungqvist J, Bail H, et al. The new proximal femoral nail antirotation (PFNA) in daily practice: results of a multicentre clinical study. Injury. 2008;39(8): 932-939.

29. Yu J, Zhang C, Li L, et al. Internal fixation treatments for intertrochanteric fracture: a systematic review and meta-analysis of randomized evidence. Sci Rep. 2015;5:18195.

30. Gormeli G, Korkmaz MF, Gormeli CA, et al. Comparison of femur intertrochanteric fracture fixation with hemiarthroplasty and proximal femoral nail systems. Ulus Travma Acil Cerrahi Derg. 2015;21(6):503508 .
31. Park BJ, Cho HM, Min WB. A comparison of internal fixation and bipolar Hemiarthroplasty for the treatment of reverse oblique intertrochanteric femoral fractures in elderly patients. Hip Pelvis. 2015;27(3):152-163.

32. Ozkayin N, Okcu G, Aktuglu K. Intertrochanteric femur fractures in the elderly treated with either proximal femur nailing or hemiarthroplasty: a prospective randomised clinical study. Injury. 2015;46:S3-S8.

33. Tang $\mathrm{P}, \mathrm{Hu} \mathrm{F}$, Shen J, et al. Proximal femoral nail antirotation versus hemiarthroplasty: a study for the treatment of intertrochanteric fractures. Injury. 2012;43(6):876-881. 